\title{
FIRMAS HETEROGÊNEAS E EXPORTAÇÕES: UMA RESENHA À LUZ DAS EVIDÊNCIAS BRASILEIRAS*
}

\author{
Sérgio Kannebley Júnior**
}

\begin{abstract}
RESUMO Esse artigo procura retratar o desenvolvimento da literatura empírica, em comércio internacional, sobre os determinantes das exportações e produtividade aplicada ao caso brasileiro. Para isso, discute sob a perspectiva dos modelos de comércio para firmas heterogêneas, alguns dos principais resultados da literatura internacional e nacional relativos às hipóteses de custos de entrada e histerese nas exportações, autosseleção para exportações e aprendizado pelas exportações, além da relação entre liberalização comercial e produtividade das firmas. Em termos gerais, o trabalho conclui que a literatura nacional segue de perto os resultados apresentados pela literatura internacional. Esses resultados favorecem a aceitação das hipóteses de histerese, de autosseleção e aprendizado pelas exportações. Porém, indica que dificilmente ocorreu para o caso brasileiro o fenômeno de realocação industrial, teoricamente considerado pela literatura, e seus consequentes impactos sobre a evolução da produtividade da indústria brasileira.
\end{abstract}

PALAVRAS-CHAVE: modelos de comércio com competição Imperfeita e economias de escala; firmas heterogêneas; produtividade; histerese em comércio internacional

\section{HETEROGENEOUS FIRMS AND EXPORTS: A REVIEW BASED ON BRAZILIAN EVIDENCES}

ABSTRACT This article tries to portray the development of the empirical literature on the determinants of trade exports and productivity applied to the Brazilian case. For this, we argue, from the perspective of trade models for heterogeneous firms, some of the main results of national and international literature relating to the hypothesis of entry costs and hysteresis in exports, self-selection and/or learning by exports and the relation between trade liberalization and productivity of firms. Overall, the

\footnotetext{
*Artigo enviado em 8 de abril de 2010 e aprovado em 18 de março de 2011.

** Professor FEA-RP/USP, Depto de Economia. Contato: skj@usp.br.
} 
paper concludes that the national literature closely follows the results reported by international literature. These results favor the acceptance of the hysteresis hypothesis, self-selection and learning by exports. However, the phenomenon of industrial reallocation, theoretically predicted in the literature, and their consequent impacts on the evolution of the productivity of Brazilian industry, did not occur in the Brazilian case.

KEY-WORDS: models of trade with imperfect competition and scale economies; heterogeneous firms; productivity; hysteresis in international trade

CóDIGOS JEL.: F12; L11 


\section{INTRODUÇÃO}

Davis e Weinsten (2001) admitem que, no campo da economia internacional, a análise empírica teve modesta influência sobre o desenvolvimento da teoria pura em comércio internacional. Diferentemente de em outras áreas em economia, como, por exemplo, na economia do trabalho, ou em macroeconomia, existiu na última metade do século XX um enorme desequilíbrio no desenvolvimento da teoria sobre os determinantes do comércio vis-à-vis a uma compreensão empírica dos fatos envolvidos nas trocas internacionais.

Esses desenvolvimentos empíricos podem ser distintos em dois grandes ramos: aqueles relacionados à busca da validade do modelo de Heckscher-Ohlin-Vanek $(\mathrm{H}-\mathrm{O}-\mathrm{V})$ e às suas predições sobre a remuneração dos fatores de produção, e aqueles relacionados à busca de evidências para comprovação das novas teorias de comércio que objetivam explicar o comércio intra-indústria entre os países.

Embora tenha sido estabelecido um consenso empírico sobre a não validade do teorema de equalização dos preços dos fatores, o mesmo não pode ser dito sobre $o$ modelo H-O-V. Após ter sido considerado inválido nos anos de 1980, sua validade foi resgatada após diversas modificações que envolveram o relaxamento das hipóteses:

i) de que os países dispunham de mesmas tecnologias, além de permitir diferenças internacionais nas produtividades dos fatores;

ii) da introdução de funções de demanda que permitem um viés em direção ao consumo de produtos domésticos;

iii) da incorporação de custos de comércio e distância;

iv) da introdução de insumos intermediários e distinção entre bens não transacionáveis e comerciáveis no mercado internacional ${ }^{1}$.

Concomitantemente aos refinamentos teóricos e empíricos sofridos pelo modelo $\mathrm{H}-\mathrm{O}-\mathrm{V}$, a nova teoria de comércio que enfatiza a presença de economias de escala e diferenciação de produto emerge nos anos 1980 . Originalmente, essa nova teoria foi motivada pela observação de que grandes fluxos de comércio ocorrem entre países com proporções de fatores similares, e que uma significante porção desse comércio ocorre na forma de comércio intra-indústria. Esse novo campo teórico de comércio internacional busca explicar esses padrões de comércio em um ambiente em que os mercados são imperfeitos, portanto, sujeitos a possibilidades de ganhos de troca provenientes da especialização em variedades distintas de um mesmo produto.

\footnotetext{
${ }^{1}$ Para uma resenha sobre os desenvolvimentos empíricos a partir dos testes para o modelo $\mathrm{H}-\mathrm{O}-\mathrm{V}$ ver, entre outros, Ribera-Batiz e Oliva (2003). Esses desenvolvimentos são analisados criticamente também em Helpman (1999) e Davis e Weinsten (2001).
} 
A despeito do fato de os principais pesquisadores da área concluírem que existem muitas questões empíricas a serem resolvidas na linha de pesquisa sobre os determinantes comércio e que, portanto, é difícil afirmar com convicção qual o papel de diversos fatores como diferenças tecnológicas, de dotação de fatores, ou dos retornos crescentes de escala na determinação dos padrões de comércio, é importante notar que a chamada nova teoria de comércio internacional estabeleceu uma trajetória de evolução que se consolidou. Partindo dos modelos estáticos de Helpman (1981) e Krugman (1979, 1980), passando pelos modelos de crescimento endógeno nos anos de 1990 com as contribuições de Grossman e Helpman (1991a, 1991b), e aos modelos de com firmas heterogêneas de Melitz (2003), Bernard et al. (2003).

A avaliação empírica desses modelos é discutida em vários surveys da área de economia internacional como, por exemplo, Helpman (1999), Leamer e Levinshon (1994), e mais recentemente por Feenstra (2006). No trabalho de Feenstra são destacados trabalhos empíricos relacionados a três fontes de ganhos de comércio preditos pelos modelos de competição monopolista:

i) a queda nos preços após uma redução tarifária proveniente da maior competição entre as firmas ${ }^{2}$;

ii) um aumento na variedade de produtos disponíveis aos consumidores;

iii) a autosseleção das firmas, em que somente as mais eficientes sobreviveriam após a liberalização comercial. Segundo esse mesmo autor, as predições sobre quedas nos preços não possuem evidências empíricas que assegurem a ocorrência desses eventos, sendo, no entanto, os casos verificados mais fortemente relacionados à diminuição da segmentação dos mercados e consequente redução da discriminação de preços. Já os itens (ii) e (iii) são aqueles que possuem evidências mais robustas.

O presente trabalho trata especificamente sobre as evidências de autosseleção para exportar, sua inicial contraposição à hipótese de aprendizado e seus desdobramentos. Essa discussão foca-se nas questões associadas à relação entre o nível de produtividade da firma, a entrada e sobrevivência no mercado exportador e tem recebido grande atenção na literatura, principalmente, posteriormente à publicação dos trabalhos de Clerides, Lach e Tybout (1998) e Bernard e Jensen (1999). Essa resenha se propõe a realizar uma discussão sobre esse tema à luz das evidências internacionais e especificamente para o caso brasileiro.

Nesse sentido esse trabalho é organizado da seguinte forma: Na primeira seção são revistos os argumentos teóricos de Melitz (2003) e Bernard, Eaton, Jensen e Kortun

\footnotetext{
${ }^{2}$ Nos modelos originais de Helpman, Krugman (1979) e Lancaster (1980) essas reduções de preços estariam relacionadas aos retornos crescentes de escala.
} 
(2003), sobre as heterogeneidades das firmas e os impactos de processos de liberalização comercial sobre a estrutura industrial dos países. Posteriormente, são avaliadas algumas contribuições recentes da literatura sobre a relação entre liberalização comercial e a evolução da produtividade das firmas. Na seção seguinte, é examinado o desenvolvimento da literatura que relaciona à presença de sunk costs na atividade exportadora à presença de histerese nas exportações. Na terceira seção são apresentados estudos sobre as hipóteses de autosseleção e aprendizado pelas exportações, sendo que na seção final são tecidas algumas considerações finais, em que são comparados os resultados obtidos para o caso brasileiro aos reportados pela literatura internacional e suas implicações sobre o desenvolvimento dessa linha de pesquisa no Brasil.

\section{MODELOS COM FIRMAS HETEROGÊNEAS}

Embora os desenvolvimentos teóricos iniciais da nova teoria de comércio considerem, diferentemente da abordagem convencional de comércio, explicitamente o papel das firmas na determinação dos padrões de comércio dos países. Isso se deu por meio de processos competitivos fundados em ambientes de concorrência imperfeita em modelos em que todas as firmas eram exportadoras. Essa característica desses modelos devia-se à simetria nas funções de produção e de utilidade e à inexistência de custos específicos à atividade exportadora ${ }^{3}$.

Entretanto, os fatos estilizados sobre o comportamento e a performance relativa das firmas exportadoras em um corte transversal de países revelam que exportadores:

1) são minoria no conjunto de firmas;

2) tendem a serem mais produtivos e maiores;

3) exportam somente uma pequena fração de sua produção.

Essas diferenças observadas entre empresas exportadoras e não exportadoras leva então à questão de qual a relação de causalidade entre exportação e ganhos de eficiência ou performance das firmas. A primeira hipótese é de que existe a autosseleção das firmas mais produtivas para os mercados externos. A razão fundamental para isso é a existência de custos adicionais para as vendas em mercados externos. O escopo desses custos inclui desde custos de transportes, de distribuição ou marketing, pessoal qualificado para lidar com redes externas até, ou custos de produção para adequação aos padrões de consumo internacional. Esses custos constituem uma

\footnotetext{
${ }^{3}$ Por simetria entendem-se todos os produtos diferenciados que entram simetricamente na função de utilidade (isto é, tem a mesma parcela de gasto no dispêndio total). Já o tratamento simétrico na oferta e na demanda implica que, em equilíbrio, todas as firmas produzem o mesmo montante de cada produto diferenciado e cobrem o mesmo preço.
} 
barreira à entrada que as empresas menos eficientes não são capazes de transpor. Adicionalmente, o comportamento da firma pode ser dirigido por uma projeção futura de participação no mercado externo, o que a levaria a melhorar sua eficiência a fim de enfrentar um ambiente de competitividade mais intensa. Sendo assim, do ponto de vista da hipótese de autosseleção, a maior permanência no mercado externo deve-se preponderantemente às condições iniciais das firmas, apresentadas anteriormente à estréia no mercado exportador. Isto é, os ganhos em termos de eficiência e qualidade já haviam sido obtidos quando da entrada no mercado externo, dando a essas empresas uma maior chance de sobrevivência à seleção natural promovida pelo ambiente externo mais competitivo.

Por outro lado, sob a hipótese de aprendizado, os ganhos de eficiência e qualidade também poderiam ser obtidos posteriormente à estréia no mercado externo. Esses ganhos seriam advindos da exposição a uma competição mais intensa, ou a melhores práticas tecnológicas e/ou gerenciais, fazendo com que sua evolução ocorresse continuadamente mesmo após sua entrada no mercado internacional. Com isso, a maior permanência na base exportadora seria explicada pelo círculo virtuoso resultante do aprendizado: quanto maior o ganho de eficiência decorrente da participação exportadora, maior a lucratividade da empresa e, portanto, maior a probabilidade de que ela permanecesse continuamente nessa atividade.

Sob o argumento da autosseleção, os modelos de Melitz (2003) e Bernard et al. (2003) são os precursores na literatura teórica de comércio internacional a fim de explicar a presença de firmas heterogêneas na indústria, bem como o impacto do comércio sobre a produtividade da indústria.

Melitz (2003) constrói um modelo de indústria dinâmico cujo objetivo é identificar o canal pelo qual o comércio intra-indústria é capaz de promover o crescimento da produtividade, a saber na redistribuição dentro da indústria de insumos e produtos em direção de firmas mais produtivas. A representação esquemática desse modelo é retratada por Falvey et al. apud Greenway e Kneller (2007) e apresentada na Figura 1. Assumindo um modelo de competição monopolista do tipo Dixit-Stiglitz (1977) é demonstrado que, em razão dos diferenciais de produtividade, embora as firmas estabeleçam um mark-up constante, as firmas mais produtivas serão maiores em produção e receita, cobrarão menores preços e obterão maiores lucros do que as firmas menos produtivas. Anteriormente à entrada na indústria as firmas entrantes em potencial são idênticas, sendo que, para entrar na indústria, devem realizar um investimento inicial, tido como um custo fixo de entrada. A fim de capturar o fato de que as firmas não têm pleno conhecimento de seu próprio nível de produtividade até o momento de começarem a produzir e a vender o seu bem, é suposto que a firma entrante retira de uma distribuição de produtividade um parâmetro de produtividade 
inicial, $\varphi$. É admitida adicionalmente a presença de custos de fixos de entrada e de atuação no mercado externo, fazendo que o preço cobrado pelas firmas domésticas no mercado externo seja superior ao cobrado no mercado doméstico.

Como resultado de um processo de determinação simultânea entre o numero máximo de firmas que a indústria é capaz de suportar e da condição de lucro zero, além da presença de custos de entrada e permanência no mercado externo, são determinados níveis limiares inferiores de produtividade para atuação no mercado

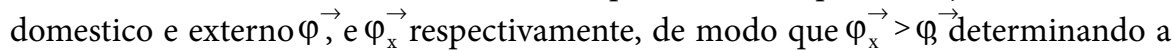
distribuição de probabilidade de produtividade das firmas ativas no mercado, $\mu(\varphi)$, e segmentando sua atuação entre os mercados doméstico e externo. A exposição ao comércio internacional eleva o limiar inferior de produtividade das firmas, aumentando, consequentemente, o nível médio de produtividade da indústria. Sendo assim, um processo de seleção ocorre em razão dos níveis de produtividade, realocando conseqüentemente parcelas de mercados em direção às firmas mais produtivas.

FIGURA 1 - INCERTEZA NA PRODUTIVIDADE E ENTRADA/SAÍDA DAS FIRMAS

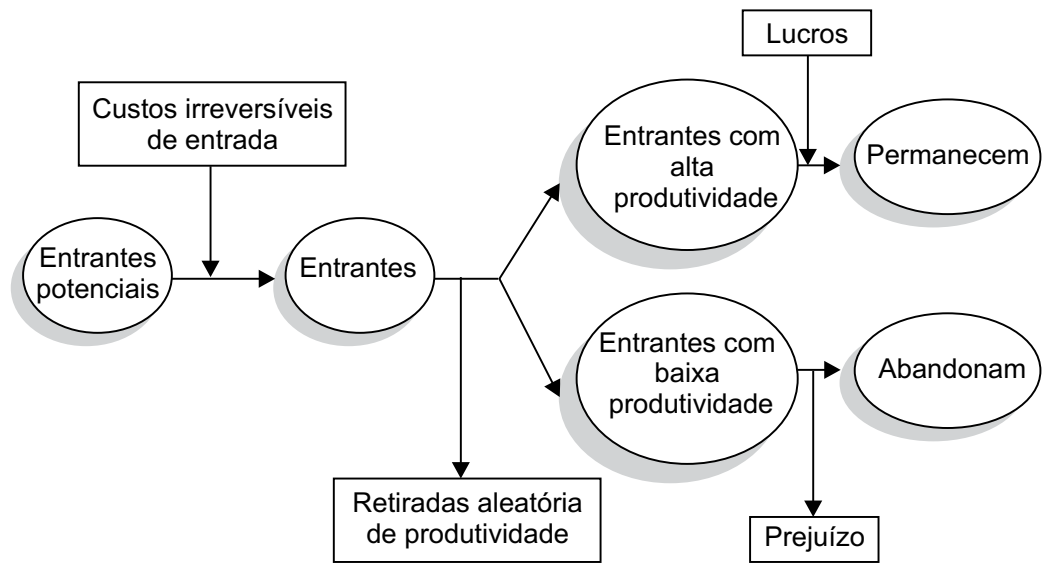

Fonte: Greenway e Kneller (2007).

A decisão de exportar é induzida pela perspectiva de aumento no lucro e marketshare em uma economia integrada (aberta). Por outro lado, para as firmas que não exportam a perspectiva de lucro e participação de mercado em uma economia aberta é de declínio. Com a abertura de mercado, em que cada firma produz uma variedade de produto, as firmas tendem a incorrer em perdas na participação no mercado doméstico. Para as firmas que não Exportam essa perda pode significar a exclusão do mercado, abrindo espaço para as firmas mais produtivas. A perda de mercado das firmas domésticas se dá pela elevação dos custos do trabalho, que ocorre em razão da maior demanda de trabalho proveniente das firmas exportadoras que expandem suas vendas para o mercado internacional, inviabilizando em alguns casos a participação 
das firmas puramente domésticas e fazendo com que fechem as portas. Sendo assim, existe um processo de seleção natural darwiniano em que as firmas mais produtivas prosperam e crescem, enquanto outras menos produtivas que não exportam podem incorrer em perdas de lucro e/ou market-share. Esse processo de realocação é ilustrado na Figura 2.

FIGURA 2 - HETEROGENEIDADE DA PRODUTIVIDADE E REALOCAÇÃO INDUSTRIAL

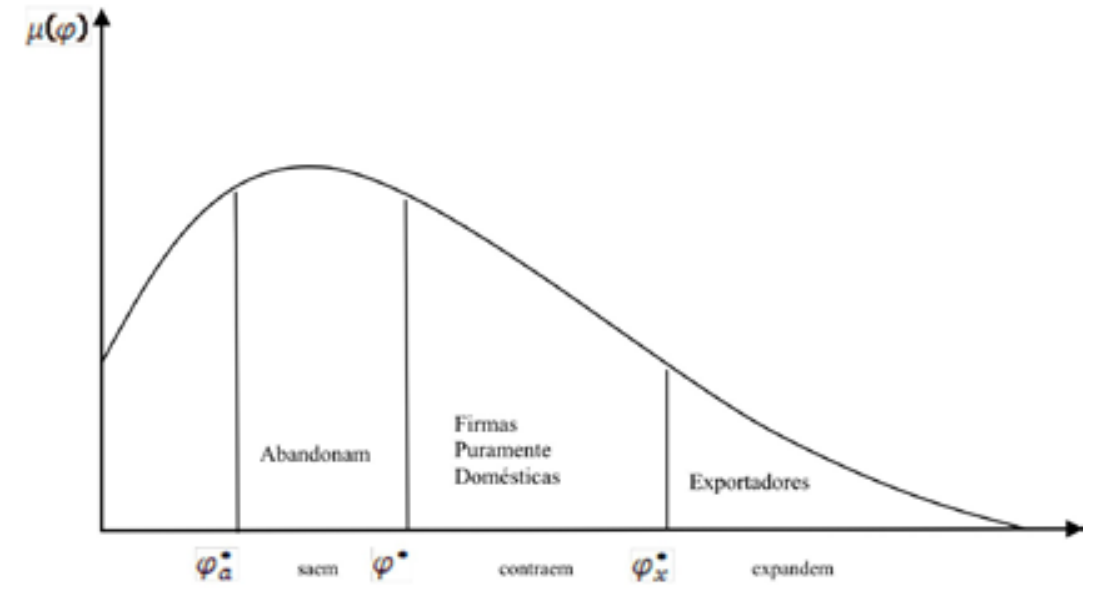

Fonte: Greenway e Kneller (2007).

Já Bernard et al. (2003) desenvolvem um modelo em que introduzem diferenças ricardianas nas eficiências técnicas dos produtores e dos países, dentro de uma abordagem probabilística para as vantagens comparativas, a fim de explicar a coexistência de plantas exportadoras e não exportadoras em um mercado. Essa coexistência é possibilitada, em parte, pela hipótese de custos de transporte específicos ao destino no comércio internacional. Isso permitiria que firmas locais, com produção destinada apenas ao mercado doméstico, permanecessem no mercado, desde que fossem suficientemente mais eficientes para superar as diferenças entre os custos dos insumos e de transportes que os concorrentes externos fariam face. Já as firmas mais eficientes, mais propensas a exportar e a serem mais produtivas, também cobrariam menores preços a fim de fazer face à concorrencial potencial. Com isso, dada uma demanda elástica, maiores são suas vendas e, portanto, estabelece-se a relação positiva entre eficiência e tamanho. Bernard et al. (2003), dentro dessa configuração de organização industrial, também demonstram que alterações no regime de comércio trariam efeitos de realocação proporcionados pela intensificação da competição das importações e pela maior penetração dos exportadores em mercados externos. 


\section{LIBERALIZAÇÃO COMERCIAL E PRODUTIVIDADE}

Os modelos de comércio internacional usualmente associam a um processo de liberalização comercial um movimento de realocação interssetorial em direção ao setor cujo país possui vantagens comparativas. Em um modelo ricardiano simples, com um fator de produção, essa realocação é capaz de produzir um aumento na produtividade à medida que a variação dos preços relativos promove o deslocamento do fator para o setor que é relativamente mais produtivo.

Já os modelos de comércio com concorrência imperfeita também predizem ganhos de comércio intra-industriais baseados em economias de escala e aumento de variedades dos produtos. A integração econômica levaria à criação de um mercado maior, em que consumidores "amantes da variedade" reduzem o consumo de cada variedade, mas, por outro lado, aumentam o número de variedades consumidas. Pelo lado das firmas haveria uma concentração da produção, na medida em que um menor número de variedades seria produzida internamente, mas devido aos ganhos de escala sancionados pelo maior mercado haveria uma recorrente redução de preços e um aumento da produtividade dos fatores ${ }^{4}$.

Adicionalmente, conforme descrito na seção acima, nos modelos de comércio com firmas heterogêneas, a liberalização comercial também tende a impactar a produtividade média da indústria. A maior exposição à concorrência internacional deve promover um processo de realocação das firmas que envolva a exclusão de firmas ineficientes e a expansão da parcela de mercados das firmas mais eficientes. Entre essas firmas mais eficientes estão justamente as firmas que estréiam no mercado internacional ou as firmas exportadoras, que expandem suas vendas externas, estabelecendo-se assim o nexo causal entre exportação e produtividade da indústria. Bernard e Jensen (2004) examinam a interação entre exportação e o crescimento da produtividade na indústria americana, utilizando dados de um painel desbalanceado com 50 mil a 60 mil firmas por ano para o período de 1983 a 1992. Por meio de um exercício de decomposição das variações da produtividade total dos fatores, no efeito da própria variação da produtividade (variação da produtividade intrafirma) e no efeito de realocação de mercado (variação do market-share), demonstra que a taxa média de crescimento da produtividade no período foi igual a $1,42 \%$, com $0,82 \%$ ( $58 \%$ do total da variação) correspondendo ao efeito da própria variação de produtividade, enquanto que $0,59 \%$

\footnotetext{
${ }^{4}$ Os ganhos internos de escala seriam provenientes da suposição de custos marginais constantes, mas custos fixos médios declinantes.
} 
( $42 \%$ do total da variação) foram devido ao efeito de realocação de market-share 5 . Seus resultados ainda demonstraram que os principais responsáveis por ambos os efeitos foram os exportadores contínuos, com a maior parte do efeito de realocação motivado pela expansão de suas vendas externas. Já Baldwin e Gu (2004), ao analisar como as firmas industriais canadenses responderam à crescente liberalização comercial ocorrida a partir de 1989 com o Acordo de Livre Comércio entre Canadá e EUA, evidenciam que a esse processo esteve associado com um substancial aumento no percentual de plantas que exportam 6 . Tendo sido demonstrado que as firmas que entram no mercado externo obtêm ganhos de produtividade ex-post à entrada, associa-se esse último resultado à possibilidade do processo de liberalização comercial ser indutor do crescimento da produtividade nesse país.

O advento da abertura comercial no Brasil ao final dos anos de 1980 e meados dos anos de 1990 incentivou a produção de vários estudos a fim de determinar como esse processo impactou a produtividade da indústria brasileira ${ }^{7}$. Conforme assinalado por diversos autores, a liberalização comercial trouxe ganhos inequívocos de produtividade. Dentre os muitos trabalhos que procuram investigar tal relação, um caso típico é o artigo de Ferreira e Rossi (2003) em que é estimado impacto da abertura comercial sobre a produtividade total dos fatores (PTF) para o agregado da indústria brasileira. Utilizando dados para o período de 1985 a 1997 para 16 setores industriais, esses autores demonstram que no período de 1985 a 1990, 10 dos 16 setores industriais apresentaram taxas negativas de crescimento da PTF (média de -3,83\% no período), mas que no período de 1990 a 1997, a PTF de 15, entre os 16 setores,

${ }^{5}$ Denotando como TFPAa produtividade total dos fatores agregada para todas as firmas da indústria, sua variação entre os períodos $\mathrm{t}-1$ e t pode ser decomposta da seguinte forma:

$\Delta \mathrm{TFP}_{\mathrm{A}}=\sum_{\mathrm{i}=1}^{\mathrm{I}} \Delta\left(\mathrm{TFP}_{\mathrm{i}} * \mathrm{SH}_{\mathrm{i}}\right)=\sum_{\mathrm{i}=1}^{\mathrm{I}} \Delta \mathrm{TFP}_{\mathrm{i}} * \overline{\mathrm{SH}_{\mathrm{i}}}+\sum_{\mathrm{i}=1}^{\mathrm{I}} \Delta \mathrm{SH}_{\mathrm{i}} * \overline{\mathrm{TFP}_{\mathrm{i}}}$

Nessa equação de variação, o primeiro termo corresponde ao efeito da variação da própria produtividade e o segundo termo ao efeito de variação realocação de mercado, sendo $\mathrm{SH}_{\mathrm{i}}$ a parcela de mercado da firma i.

${ }^{6}$ Seus resultados, obtidos a partir de informações de plantas industriais para o período de 1984 a 1996, indicaram que o declínio em 4,5 pontos percentuais nas tarifas canadenses no período de 1990-1996 estaria associado com um aumento em $24 \%$ da chance de que uma planta representativa (média) viesse a participar do mercado externo. Adicionalmente, reportam que as firmas maiores, mais jovens e mais produtivas são aquelas mais propensas a entrar no mercado externo, indicando, portanto, um resultado de autosseleção.

${ }^{7}$ Sintetizando, o processo de liberalização comercial brasileiro envolveu uma significativa mudança na estrutura tarifária brasileira, além da remoção de diversão barreiras não tarifárias. Conforme relata Cavalcanti e Ferreira, no período de 1988 a 1997 a tarifa nominal média declinou de 118 pontos percentuais para aproximadamente 13 pontos percentuais, havendo também ocorrido substantiva redução da variabilidade entre os setores industriais. Já a taxa média de proteção efetiva da indústria declinou de 85,8\% em 1987 para 17,7\% em 1997. Markwald (2001) destaca, entretanto, que o fato demarcador da transição para um regime aberto de comércio foi a extinção das barreiras não-tarifárias. 
cresceu a taxas anuais superiores a $2,65 \%$. Suas estimativas indicam que a redução das tarifas nominais pode ter levado a um acréscimo na taxa de crescimento da PTF entre $8 \%$ a $12 \%$, enquanto que o impacto da redução da taxa de proteção efetiva teria levado a um aumento na taxa de crescimento da PTF de 3\% a 6\%.

Castro (2001) oferece uma interpretação para o processo de reorganização industrial ocorrido após a liberalização comercial. Segundo esse autor, esse processo de reestruturação subentendeu diferentes formas de ajuste à maior pressão competitiva internacional trazida pela abertura comercial, que ocorreram mais ou menos intensamente em diferentes momentos desse processo. Assim, no período de sua implantação, ocorrida entre o final dos anos de 1980 até 1994, com o lançamento do Plano Real, em razão de um ambiente econômico altamente e cronicamente instável, tendeu a haver um relativo imobilismo das empresas frente ao novo estado competitivo, gerando, por parte das empresas, uma reação típica baseada na reorganização produtiva, com ênfase na modernização de procedimentos gerenciais e estratégias de atuação, introduzidas com o objetivo de redução de custos ${ }^{8}$.

Após a estabilização, com a revitalização do mercado doméstico, além do prosseguimento da reestruturação, as respostas centraram-se na modernização/diversificação dos produtos, o que ensejou o aumento das importações de insumos e equipamentos com o intuito de baratear e acelerar a absorção da tecnologia contida nos novos processos e produtos. Também ocorreu nessa etapa um processo de relocalização industrial, com o objetivo de explorar vantagens comparativas locais e aspectos locacionais como a proximidade aos mercados ${ }^{9}$. Dessa maneira, nessa segunda fase de reestruturação, o uso de novos insumos e a aquisição de máquinas e equipamentos assume importância decisiva. Ainda segundo Castro (2001), os “pífios” resultados obtidos pelas exportações no período não seriam apenas devidos à valorização cambial verificada, mas ao fato de que as mudanças no período faziam com que as firmas voltassem suas atenções e estratégias para o mercado doméstico. A forma de catch-up produtivo liderado pela busca de eficiência e renovação, deixando pouco espaço para a iniciativa inovadora, tornava relativamente custosa a busca de novos mercados no exterior; sendo assim, nesse período, as firmas centraram-se no fortalecimento de suas posições no mercado doméstico.

\footnotetext{
${ }^{8}$ Segundo o autor, nesse período, denominado de cirurgia e reorganização, predominaram práticas como o redimensionamento de quadros, enxugamento do catálogo de vendas e o fechamento de instalações, além da adoção de novas práticas de gestão tipicamente associadas à prática de Gerência da Qualidade Total. Ainda segundo as próprias palavras de Castro (2001), "A economia brasileira viveu, neste primeiro período, o equivalente de uma abertura travada.(...)a proximidade do caos hiperinflacionário reduzia a capacidade dos agentes econômicos de exercer a contestação".

${ }^{9}$ É importante esclarecer que, segundo Castro (2001), esse tipo de reação representou também uma estratégia de catch-up produtivo.
} 
Essa interpretação encontra ressonância em outros estudos como os de Fonseca et al. (2001) e de Markwald (2001). No primeiro artigo, são calculados indicadores de orientação externa para a indústria brasileira a fim de melhor compreenderem as mudanças na orientação comercial da indústria nos anos de 1990. Fonseca et al. (2000) demonstram que, enquanto o coeficiente de exportações para a indústria de transformação no período de 1989 a 1998 apresentou relativa estabilidade, com valores de 9,1 \% e 10,8\% para os respectivos triênios de 1989-1991 e 1996-1998, os coeficientes de penetração de importações e de participação de insumos importados apresentaram aumentos significativos no período. $\mathrm{O}$ coeficiente de penetração de importações passou de 4,9\% no triênio de $1989-1991$ para $12,1 \%$ no triênio de 1996-1998, enquanto que o coeficiente de participação de insumos importados saltou de 3,6\% no triênio de 1989-1991 para a média de 5,7\% no triênio de 1996-1998. Ainda demonstram que a estrutura de comércio setorial sofreu mais intensamente alterações a partir dos anos de 1992 e 1993, com a consolidação dos cortes tarifários, e que o maior impacto estrutural ocorreu no coeficiente de insumos importados. Já Markwald (2001) demonstra, inclusive, que entre 1992 e 1997-1998 as firmas menores apresentaram aumentos mais expressivos na propensão a importar que as empresas grandes ${ }^{10}$. Pelo lado das exportações, ainda que seus cálculos indiquem uma variação um pouco mais expressiva no coeficiente agregado de exportação, por parte das firmas não houve expressiva alteração na propensão a exportar. Seus cálculos indicam, inclusive, uma ligeira redução para o total das empresas exportadoras, de 18\% em 1992 para uma média de 16\% no biênio de 1997-1998.

Muendler (2004) procura avaliar os impactos da liberalização comercial sobre as firmas industriais brasileiras. Utilizando um banco de dados em painel desbalanceado com aproximadamente 9.500 firmas industriais com 30 ou mais funcionários de 27 setores industriais brasileiros, para o período de 1986 a 1998, inquire sobre os possíveis canais em que a redução das barreiras tarifárias e não-tarifárias pudesse afetar a produtividade total dos fatores de firmas. Seus resultados, obtidos por meio de procedimentos econométricos e de simulação, indicam que o efeito de pressão competitiva sobre o mercado de produtos foi o mais relevante. Sua estimativa foi de que aproximadamente 16\% do aumento da produtividade total dos fatores, ocorrido entre 1990 e 1998, deveram-se ao aumento da pressão competitiva. Sua conclusão quanto à maior disponibilidade de equipamentos e insumos estrangeiros posteriormente à abertura comercial foi de que, em média, em razão da necessidade de desenvolvimento de algum aprendizado

\footnotetext{
${ }^{10}$ Segundo as evidências fornecidas por esse autor, a propensão média a importar das empresas pequenas e médias saltou de 2,5\% e 4,8\% respectivamente, para $12,8 \%$ e $11,2 \%$ na média do biênio de 1997-1998. Já as grandes empresas importavam 10,3\% do seu valor produzido em 1992 e passaram a importar 13,7\% no biênio 1997-1998.
} 
ou outros custos de implementação de tecnologias incorporadas em insumos ou equipamentos estrangeiros, os setores industriais falharam em implementar eficientemente, ao menos no curto prazo, essa nova fonte de recursos. Quanto ao canal de eliminação competitiva, suas estimativas indicaram uma relação entre uma menor produtividade das firmas e a maior chance de saírem do mercado após a redução tarifária. Contudo, o impacto da eliminação das firmas menos produtivas foi negligenciável em termos de variação da produtividade total dos fatores. Já Schor (2004), utilizando base de dados semelhante, ao discriminar os efeitos da liberalização provenientes da maior competição no mercado de bens finais de consumos e da redução de custos ou intensificação da competição no mercado de bens intermediários e de capital, conclui que o efeito das tarifas nominais foi inferior ao das tarifas dos insumos sobre a produtividade. $\mathrm{Ou}$ seja, conclui que o impacto do aumento da competição sobre a produtividade não foi superior ao impacto da possibilidade do uso de insumos importados na produção. Esse resultado é reforçado pelas recentes evidências fornecidas por Lisboa, Menezes Filho e Schor (2010), que mostram que o mercado de insumos foi mais importante que o efeito da concorrência para explicar o crescimento da produtividade no Brasil decorrente da liberalização comercial. Adicionalmente, também foi verificado nesse estudo que a redução das tarifas de insumo aumentou as margens de lucro das firmas industriais, enquanto a redução de tarifas de produto teve efeito oposto.

Uma possível explicação para a diferença nos resultados proporcionados por Muendler (2004) e Schor (2004), pode ser encontrada na periodização proposta por Castro (2001) e Fonseca et al. (2001) para adoção de novos insumos e de equipamentos importados e propriamente a programação de redução de tarifas, que se encerra em 1993. É possível que os testes de Muendler (2004) tivessem seu poder reduzido em razão dessa relativa defasagem na ocorrência desse canal de influência sobre a produtividade dos fatores, enquanto que o mesmo não tenha ocorrido para os testes de Schor (2004). Com isso, ao ser admitida a validade dos resultados de Schor (2004), o que pode ser dito sobre essa diferença seria de que a estratégia metodológica de Schor (2004) de desmembramento das tarifas nominais e de insumos foi mais eficiente para identificar os efeitos desse canal.

Assim sendo, os resultados aqui reportados indicam que os ganhos de produtividade foram proporcionados, principalmente, por dois canais, quais sejam: o aumento da pressão competitiva das importações sobre os mercados de bens, que levou as firmas a reagirem buscando racionalizar seus sistemas de produção e atividades, e a crescente adoção de insumos e equipamentos importados, que permitiu uma busca mais rápida por padrões produtivos de excelência internacionais, além da renovação de produtos a fim de capacitar as firmas a concorrerem com os bens importados. Aparentemente, esse aumento de produtividade também seria proveniente em sua maior parte das empresas que continuaram na base industrial. Entretanto, contrariamente ao esperado, 
foi mais intenso na parte inferior da distribuição de produtividade das firmas. Por fim, ainda que não tenha sido produzido nenhum estudo sobre o impacto da realocação de mercado sobre a produtividade, diversos indicadores, combinado ao fato de que muito provavelmente as empresas exportadoras situam-se na parte superior da distribuição de produtividade das firmas, sugerem que muito dificilmente o aumento de produtividade verificado tenha sido resultante desse canal de influência.

\section{SUNKCOSTS E HISTERESE: MICRO EVIDÊNCIAS}

Segundo Krugman (1989), a ideia básica do modelo de custos irrecuperáveis "é de que o comércio não se dá de forma fácil". Ou seja, além dos fatores competitivos determinantes em modelos de concorrência imperfeita, devem ser considerados na decisão de exportar, ou deixar de exportar, os custos de entrada e saída do mercado externo. Estes custos devem-se aos investimentos em adaptação dos produtos aos mercados locais, gastos com propaganda e marketing no estabelecimento da marca, criação de redes de distribuição e capacidades de produção adequadas às necessidades de consumo dos compradores internacionais, entre outros.

$\mathrm{Na}$ presença de custos irrecuperáveis, as decisões de entrar, ou sair, do mercado devem ser avaliadas de forma prospectiva, buscando-se compreender a natureza transitória ou permanente das mudanças dos retornos esperados. Em um modelo para a exportação, mantendo-se tudo o mais constante, o cálculo dos retornos esperados e sua variância estão diretamente relacionados ao nível corrente, e esperado, da taxa de câmbio e à sua variabilidade. A decisão de entrada somente será realizada se o exportador entender que os ganhos com essa atividade excedam não apenas os seus custos variáveis, mas também estes custos irrecuperáveis. De modo inverso, a decisão de saída somente ocorrerá no momento em que os prejuízos esperados sejam capazes de sobrepujar, inclusive, os custos de saída do mercado externo. Com isso, são criados valores limiares para entrada e saída, caracterizados por lucros, ou prejuízos, acima das taxas normais.

A incerteza cambial, somada à existência de custos irrecuperáveis, leva à criação de uma zona de inação. Caso os lucros/prejuízos correntes encontrem-se nessa zona, o comportamento ótimo dos exportadores será adotar uma estratégia do tipo "esperar e ver", postergando suas decisões de entrada e saída. Segundo Dixit (1989), a decisão de entrada e saída das firmas no mercado internacional pode ser entendida como o exercício de opções de compra e venda no mercado futuro ${ }^{11}$. De modo semelhante a esses mercados de ativos, os exportadores somente exercerão suas opções de

\footnotetext{
${ }^{11}$ A oportunidade de investimento é análoga a uma opção de compra. Ela fornece o direito de realizar um investimento (o preço de exercício de uma opção) e receber o valor do projeto (ativo) que flutua estocasticamente.
} 
compra (entrada no mercado), ou venda (saída do mercado), dados os parâmetros para a precificação dos ativos, se os seus payoffs superarem os custos de exercício das opções e de oportunidade do investimento trazidos pela incerteza cambial.

Empiricamente, os testes para hipótese de histerese em comércio internacional podem ser distintos em testes em nível microeconômico, quando considerada a decisão individual da firma de entrar/sair do comércio internacional, e em testes de nível macroeconômico, quando são consideradas variáveis representativas de comércio de forma agregada.

Essa distinção em nível micro ou macro de histerese tem implicações sobre a configurações dos testes à medida que envolve diferentes modelos de histerese e, consequentemente, estratégias empíricas para condução dos testes. Göcke (2002) produz uma síntese dos modelos de histerese em economia, argumentando que o modelo de Preisach (Mayergoyz, 1986), desenvolvido na primeira metade do século XX para descrever o fenômeno de ferro-magnetismo, encontra grande aplicabilidade para a descrição do fenômeno de histerese em comércio internacional. Entretanto, dado o primordial interesse no comportamento microeconômico das firmas em comércio internacional, a discussão somente será focada na primeira forma de testes.

Em nível microeconômico, a forma usual do fenômeno de histerese estaria relacionada ao conversor de histerese chamado de non-ideal relay (relé não ideal). Uma possível ilustração para esse conceito é sua aplicação microeconômica para a decisão de uma firma por exportar. Supondo, por simplificação, uma firma tomadora de preços no mercado internacional e que tem em sua função de custos dois componentes: um variável, associado à produção, e outro fixo, associado ao custo de entrada ou saída do mercado externo. Admita que na ausência desses custos exista um valor para a taxa de câmbio, $\xi_{c}$, definida como o preço em moeda doméstica da moeda estrangeira, que torne o preço de seu produto em moeda doméstica exatamente suficiente para cobrir seus custos variáveis de produção. Assim, qualquer desvalorização da taxa de câmbio que elevasse o preço em moeda doméstica de modo suficiente para cobrir os custos variáveis de produção induziria essa firma a entrar no mercado doméstico. De forma similar, uma valorização da taxa de câmbio que fizesse com que o valor da taxa de câmbio fosse inferior a esse valor limiar induziria a firma a sair do mercado externo.

Agora supondo a existência de custos fixos de entrada no mercado externo, firmas que não operavam previamente nesse mercado terão que arcar com esses custos. Essas despesas não poderão ser recuperadas, sendo tratadas ex-post como custos irrecuperáveis (sunk costs). Sendo assim, em um ambiente sem incerteza, para que esse potencial entrante no mercado externo decida por ingressar no mercado, a desvalorização da taxa de câmbio deve superar o valor $\xi$ c, de modo a permitir que o preço cubra não apenas os custos de produção, como também os custos de entrada. Denote 
por $\beta$ esse valor, sendo $\beta>\xi c$. Analogamente, uma firma já operante nesse mercado externo somente se retirará do mercado externo na ocorrência de uma valorização cambial que reduza o preço em moeda doméstica a tal ponto que suas perdas superem não apenas os prejuízos operacionais, mas também aos custos de saída desse mercado. Denote o valor dessa taxa de câmbio por $\alpha$, sendo $\alpha<\xi$ c. A região entre dos valores $\alpha<\xi c<\beta$ é chamada banda de inação. O status de atividade da firma, quando os valores da taxa de câmbio variam dentro desse intervalo,é dependente do seu estado anterior, tornando-o estado dependente. Em nível microeconômico apenas variações significativas da taxa de câmbio que façam com que os valores da banda de inação sejam ultrapassados é que provocarão a entrada ou saída do mercado externo, gerando um comportamento não linear de resposta às variações cambiais.

$\mathrm{Na}$ presença de incerteza, as decisões de entrada e/ou saída podem ser entendidas como um investimento irreversível. Nesse caso, a abordagem de opções reais é aplicável. Se a firma tem a opção de postergar sua decisão, então é possível limitar o risco por meio de uma estratégia de esperar e ver. Nesse caso, adicionalmente aos custos fixos de entrada e saída, o valor limiar da taxa de câmbio é ampliado de forma a cobrir o valor da opção de esperar ${ }^{12}$. Dessa forma, a presença de incerteza leva à expansão da região de inação. A descrição desse mecanismo se encontra na Figura 3.

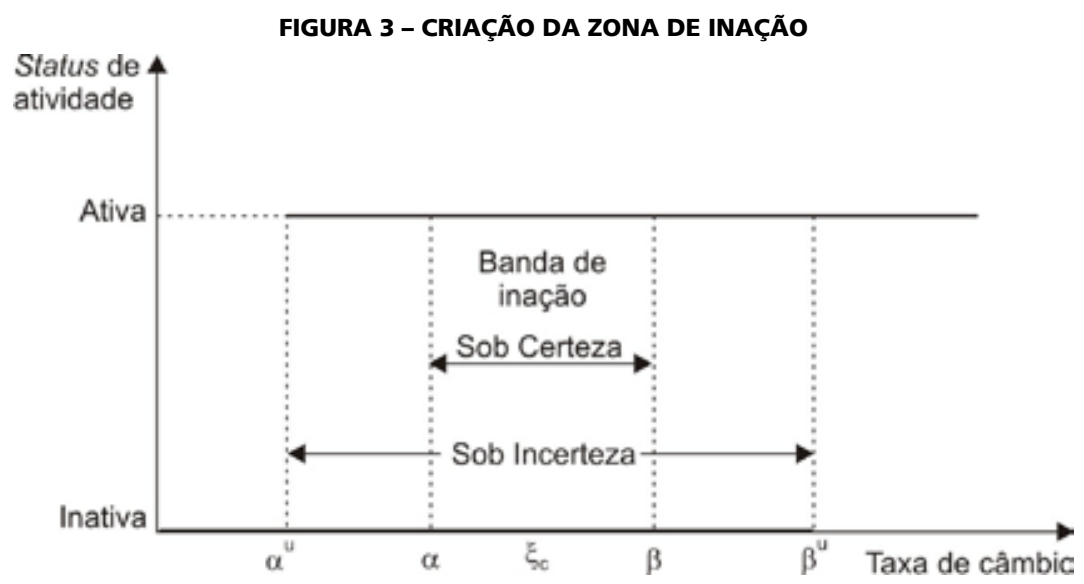

\footnotetext{
${ }^{12}$ Bernand e Jensen (2004) incluem em seu modelo variáveis representativas para taxa real de câmbio e de efeitos de transbordamentos e subsídios à exportação. Já Campa (2004) tem como objetivo analisar também as respostas dos exportadores espanhóis às variações da taxa de câmbio ao longo do período, considerando dois movimentos distintos: i) a decisão de entrada ou saída das firmas no mercado externo e; ii) o ajuste das quantidades ofertadas dos exportadores às variações cambiais.
} 
Os testes para a presença de custos irreversíveis de entrada e saída (sunkcosts) no mercado externo têm sido conduzidos em nível microeconômico com base na proposição metodológica de Roberts e Tybout (1997). Baseado na concepção microeconômica de histerese apresentada anteriormente, esses autores desenvolvem um modelo de histerese para comércio exterior com horizonte infinito. Utilizado em diversos trabalhos, esse modelo assume que a firma é capaz de escolher seu nível ótimo de produto destinado à exportação e que existem custos fixos de entrada $(\mathrm{N})$ no mercado externo. A firma considera seus lucros correntes e futuros, de modo que no período $\mathrm{t}$ a firma escolhe exportar ou não de modo a maximizar o valor presente esperado dos lucros, $\pi$, provenientes da atividade exportadora, dado por:

$$
\mathrm{V}_{\mathrm{it}}\left(\Omega_{\mathrm{it}}\right)=\max _{\mathrm{q}_{\mathrm{it}}^{*}} \mathrm{E}\left[\sum_{\mathrm{j}=\mathrm{t}}^{\infty} \delta^{\mathrm{j}-\mathrm{t}} \pi_{\mathrm{ij}}\left(\mathrm{X}_{\mathrm{t}}, \mathrm{Z}_{\mathrm{ij}}\right) \mid \Omega_{\mathrm{ij}}\right]
$$

em que $\Omega_{\mathrm{jt}}$ é o conjunto de informações disponíveis em $\mathrm{t}$, $\delta$ é o fator de desconto para um período e $\pi_{\mathrm{ij}}$ é a receita líquida esperada da firma i no período $\mathrm{j}^{13}$. A firma irá escolher exportar no período t se as receitas correntes das exportações, somadas à variação líquida do valor descontado da empresa, associadas a sua decisão de exportar, superarem os custos de produção e os custos irrecuperáveis de entrada, ou seja:

$$
\Pi_{\mathrm{ij}}\left(\mathrm{X}_{\mathrm{t}}, \mathrm{Z}_{\mathrm{it}}\right)+\delta\left[\left(\mathrm{E}_{\mathrm{t}}\left(\mathrm{V}_{\mathrm{i}, \mathrm{t}+1}\left(\Omega_{\mathrm{it}}\right)\right) \mid \mathrm{Y}_{\mathrm{it}}=1\right)-\left(\mathrm{E}_{\mathrm{t}}\left(\mathrm{V}_{\mathrm{i}, \mathrm{t}+1}\left(\Omega_{\mathrm{it}}\right)\right) \mid \mathrm{Y}_{\mathrm{it}}=0\right)\right] \geq \mathrm{c}_{\mathrm{it}}+\mathrm{N}_{\mathrm{it}}\left(1-\mathrm{Y}_{\mathrm{it}-1}\right)
$$

Com isso, a decisão de participação no mercado externo $\mathrm{Y}_{\mathrm{it}}$ expressa em (2) pode ser sumarizada por meio do seguinte modelo de escolha dinâmica:

$$
\mathrm{Y}_{\mathrm{it}}= \begin{cases}1 & \text { se } \pi_{\mathrm{it}}^{*}>\mathrm{c}_{\mathrm{it}}+\mathrm{N}_{\mathrm{it}}\left(1-\mathrm{Y}_{\mathrm{i}, \mathrm{t}-1}\right) \\ 0 & \text { caso contrario }\end{cases}
$$

em que $\Pi_{\mathrm{it}}^{\overrightarrow{\mathrm{t}}}=\Pi_{\mathrm{ij}}\left(\mathrm{X}_{\mathrm{t}}, \mathrm{Z}_{\mathrm{it}}\right)+\delta\left[\left(\mathrm{E}_{\mathrm{t}}\left(\mathrm{V}_{\mathrm{i}, \mathrm{t}+1}\left(\Omega_{\mathrm{it}}\right)\right) \mid \mathrm{Y}_{\mathrm{it}}=1\right)-\left(\mathrm{E}_{\mathrm{t}}\left(\mathrm{V}_{\mathrm{i}, \mathrm{t}+1}\left(\Omega_{\mathrm{it}}\right)\right) \mid \mathrm{Y}_{\mathrm{it}}=0\right)\right]$

Segundo a expressão (2), uma firma irá exportar desde que o lado esquerdo da equação seja superior ao lado direito da equação. O lado esquerdo captura os benefícios da exportação. Na ausência de custos de entrada e saída, o termo entre colchetes torna-se igual a zero e a decisão de exportar retorna a um padrão estático. Com isso, a decisão de entrada (e saída) no mercado externo torna-se independente da história exportadora passada. No entanto, se os custos irrecuperáveis são relevantes, eles devem aparecer em cada condição de participação da firma no mercado externo

\footnotetext{
${ }^{13}$ As receitas líquidas de exportação são dadas por $\pi_{i t}\left(X_{t}, Z_{i t}\right)=p_{t} q_{i t}^{*}-c_{i t}\left(X_{t}, Z_{i t}, q_{i t}^{*}\right)-N\left(1-Y_{i, t-1}\right) e m$ que $X_{t}$ são fatores exógenos que afetam a probabilidade de exportar, entre os quais a taxa de câmbio $Z_{i t}$ são fatores específicos à empresa que também afetam sua lucratividade e $\mathrm{Y}_{\mathrm{i}, \mathrm{t}-1}$ representa o status exportador no período anterior.
} 
e seus efeitos sobre a decisão de exportar seriam captados pelos coeficientes associados às variáveis binárias dependentes defasadas, formalizando, então, o problema da persistência.

Roberts e Tybout (1997), utilizando uma amostra de 650 plantas industriais para o período 1981-1989, apresentam evidências favoráveis à hipótese de existência de histerese para as empresas exportadoras colombianas. Essa hipótese também é aceita nos trabalhos de Clerides, Tybout e Lachs (1998), ao investigarem a hipótese de aprendizado para firmas colombianas, marroquinas e mexicanas, no período 19811991. Bernard e Jensen (2004) e Campa (2004), adotando um modelo de escolha discreta dinâmica similar àquele utilizado por Robert e Tybout, porém introduzindo novas variáveis à especificação original, também encontram evidências de histerese para 13.500 plantas industriais americanas, e para uma amostra de 2.188 de empresas industriais espanholas, respectivamente, nos períodos 1984-1993 e 1990-199714.

Para o caso brasileiro, a suspeita de existência de histerese nas exportações foi levantada, inicialmente, por Motta Veiga e Markwald (1998) e Markwald e Puga (2002) em estudos que buscavam avaliar questões relativas à base exportadora brasileira. Nesses estudos, é argumentado que o fenômeno de baixa resposta das exportações manufaturadas às mudanças de nível da taxa real de câmbio seria fruto de uma relação assimétrica das exportações com as variações cambiais, com o efeito positivo de períodos de desvalorização cambial mostrando-se mais efetivo que o impacto negativo da apreciação. Assim sendo, por trás do crescimento tendencial das exportações de produtos manufaturados, estaria um fenômeno de alargamento progressivo da base exportadora que ocorreu de modo mais intenso nos períodos de desvalorização cambial. As evidências econométricas produzidas a partir da estimação de modelos de escolha discreta dinâmica segundo a especificação (2') acima, foram obtidas por Kannebley e Vareli (2006) e Kannebley et al. (2009). Esses autores demonstram que a persistência na atividade exportadora é determinada tanto por fatores específicos às empresas, como por aqueles relacionados à experiência passada, ou a custos de entrada e/ou saída da atividade exportadora, além de que os custos de entrada/saída para o mercado externo são mais relevantes para as pequenas e médias empresas.

\footnotetext{
${ }^{14}$ Bernand e Jensen (2004) incluem em seu modelo variáveis representativas para taxa real de câmbio e de efeitos de transbordamentos e subsídios à exportação. Já Campa (2004) tem como objetivo analisar também as respostas dos exportadores espanhóis às variações da taxa de câmbio ao longo do período, considerando dois movimentos distintos: i) a decisão de entrada ou saída das firmas no mercado externo e; ii) o ajuste das quantidades ofertadas dos exportadores às variações cambiais.
} 


\section{EXPORTAÇÃO E PRODUTIVIDADE: EVIDÊNCIAS PARA AUTOSSELEÇÃO E/OU APRENDIZADO}

Tendo sido a presença de custos de entrada e saída em mercados internacionais evidenciada por uma grande gama de estudos, isto forneceu argumentos a favor da hipótese de autosseleção. Com isso, a pesquisa foi direcionada para testar as hipóteses de autosseleção e learning by exporting como explicativa dos diferenciais de produtividade entre as empresas exportadoras e não exportadoras.

Os trabalhos de Clerides, Lach e Tybout (1998) e Bernard e Jensen (1999) foram os grandes precursores dessa linha de pesquisa. O primeiro trabalho utiliza bases de dados em painéis balanceados de plantas industriais de firmas do México (1986-1990), Colômbia (1981-1991) e Marrocos (1984-1991), a fim de produzir evidências para:

i) aprendizado pelas exportações;

ii) efeitos de externalidade das atividades de exportação sobre as firmas não exportadoras ou mercados regionais.

Seus resultados, a partir de estimações de modelos de equações simultâneas para a decisão de entrada e da função de custos médio das firmas em indústrias exportadoras intensivas, forneceram evidências escassas de aprendizado pelas exportações, levando aos autores concluírem que a participação no mercado externo não é capaz de afetar a trajetória de custos das firmas. Com relação à presença de transbordamentos da atividade exportadora indústria em específico, ou, em termo, regionais, suas evidências revelaram, principalmente, que firmas não exportadoras em indústrias, ou regiões, tendem a se beneficiar em eficiência, ou em custos, quando a participação de empresas exportadoras nessas indústrias ou regiões aumentam.

Já Bernard e Jensen (1999), utilizando dados de plantas industriais da economia americana no período 1984-1992, organizam um trabalho que se divide em duas grandes partes:

i) a primeira destinada a demonstrar que a superioridade das características observáveis dos exportadores já existia antes da entrada dos exportadores no mercado externo;

ii) a segunda destinada a produzir evidências para a relação entre o status exportador e o subsequente desempenho da firma após a entrada no mercado externo.

Com relação à primeira parte, isto é demonstrado a partir de estimativas do prêmio de exportação controlando para diversas características observáveis, como tamanho, produtividade, salários etc., para um período de três anos antes da entrada no mercado externo, além de demonstrar via estimação de um modelo de decisão de exportar, que medidas defasadas de produtividade, salário e tamanho eram capazes 
de explicar a decisão corrente de exportar. Para a segunda parte, os autores descobrem que os ganhos após a entrada no mercado externo concentram-se, principalmente, em termos de tamanho da empresa, ocorrendo nos anos iniciais após a entrada. Não há evidências de ganhos de produtividade após a entrada no mercado externo. Examinando as transições das firmas industriais, entre mercado doméstico e externo, percebe-se que as variações positivas nos indicadores de produtividade e tamanho concentravam-se no grupo de empresas estreantes no mercado externo, enquanto que as variações negativas desses mesmos indicadores eram provenientes das firmas desistentes no mercado externo, não havendo diferença entre os indicadores das firmas que permaneciam no mercado continuamente e aquelas que eram exportadoras ocasionais. Também foi demonstrado que as empresas exportadoras têm maior chance de sobrevivência, sendo $10 \%$ maior essa chance em relação a uma firma não exportadora.

Wagner (2007) produz uma resenha de 54 trabalhos que abordam a relação entre exportação e produtividade para 34 países. Em termos gerais, os resultados apresentados nessa resenha tendem a confirmar as diferenças em níveis e em taxas de crescimento da produtividade entre exportadores e não exportadores e que as firmas mais produtivas tendem a se autosselecionar para o mercado externo. Ou seja, futuros estreantes no mercado externo tendem a apresentar diferenciais positivos de produtividade, em relação às firmas não exportadoras, antes propriamente de sua entrada nesses mercados. Com relação à hipótese de aprendizado pelas exportações, os resultados ainda são ambíguos, não permitindo descartar por completo essa hipótese.

Entretanto, a literatura empírica aponta a maior ocorrência de resultados favoráveis à hipótese de aprendizado para países em desenvolvimento. Isso poderia se dever, segundo Blalock e Gertler (2004), ao fato de que, nos países menos desenvolvidos, onde o acesso à tecnologia é mais restrito e as firmas estão mais distantes da fronteira tecnológica mundial, a exposição das firmas ao mercado internacional poderia apresentar maiores benefícios marginais. Van Biesebroeck (2005) também argumenta que em países em desenvolvimento aumenta a chance de ocorrências de problemas relacionados a risco de crédito e de cumprimentos dos contratos. Sendo assim, firmas que passam a atuar no mercado externo diminuem suas restrições referentes a esses fatores, obtendo, consequentemente, aumento de produtividade via ganhos de escala. Lopez (2004 apud ALVAREZ e LOPEZ, 2005) propõe ainda o argumento de que a autosseleção em países em desenvolvimento pode ser um processo consciente das firmas, pelo qual aumentam sua produtividade com o propósito explícito de se tornarem exportadores. A razão para tal esforço consciente seria porque os bens produzidos nesses países, em particular exportado para países desenvolvidos, são usualmente de melhor qualidade do que aqueles produzidos para o mercado doméstico. Sendo assim, as firmas que pretendem participar do mercado externo 
devem adquirir novas tecnologias e investir em bens de capital para uma versão de exportação para o seu bem. Essa introdução de novas tecnologias leva a um aumento da produtividade dos exportadores vis-à-vis os não exportadores, que continuam produzindo bens de menor qualidade para o mercado interno.

O argumento de Lopez (2004) é interpretado por Greenaway e Kneller (2007) como uma transição da discussão que foi realizada na literatura, que inicialmente se preocupava em testar a hipótese de autosseleção versus aprendizado, para uma hipótese de autosseleção versus uma relação bi-causal. Isto é, dada a evidência de características superiores dos exportadores frente aos não exportadores, a pergunta de pesquisa passa a ser se essas características superiores levaram as firmas a exportar, ou então se essas firmas buscaram o aumento de produtividade em razão da decisão de exportar em uma estratégia de aprendizado para exportar. Isso implicaria uma mudança de concepção de variações exógenas para variações endógenas na produtividade associada com a exportação, o que relaciona essa literatura à relação entre inovação tecnológica e exportação ${ }^{15}$. Com isso, uma questão central nessa análise passa a ser o timing da decisão, algo que não é observado em estudos com microdados.

Outra questão apenas recentemente considerada nos estudos é o esforço tecnológico empreendido pelas empresas para absorver, assimilar e gerenciar a mudança tecnológica. Esses esforços seriam direcionados à aquisição de tecnologia estrangeira, sendo que para sua melhor compreensão seria importante entender as capacidades heterogêneas das firmas em assimilarem novas informações. Aw, Roberts e Winston (2007) argumentam, com base em teorias para o desenvolvimento tecnológico das empresas, que o desenvolvimento de expertises e habilidades das firmas se dá em razão de investimentos continuados em P\&D e treinamento de pessoal. Sendo assim, esses autores procuraram verificar como a participação nessas atividades influencia a trajetória futura da produtividade das firmas. Utilizando um painel de dados, para a indústria de produtos eletrônicos de Taiwan no período 1986-1996, concluem que, além das evidências usuais concernentes à hipótese de, as firmas exportadoras se beneficiam da tecnologia que é transferida pelos clientes internacionais. Seus resultados indicam que firmas que investem em atividades de P\&D e treinamento têm uma produtividade futura significativamente superior à das empresas que apenas exportam, o que os leva a concluir que essas atividades habilitam as firmas a melhor explorarem os benefícios de sua exposição nos mercados internacionais. Resultados semelhantes haviam sidos obtidos por Baldwin e Gu (2004), ao evidenciarem, para as

\footnotetext{
${ }^{15}$ Para mais esclarecimentos, uma síntese desses estudos é apresentada em Rooper e Love (2002).
} 
firmas industriais canadenses, que os estreantes no mercado externo demonstraram uma atividade inovadora mais intensa tanto antes quanto depois da entrada no mercado externo. Contudo, com sua entrada no mercado externo alteraram seu acesso e uso de tecnologias estrangeiras, investindo complementarmente para isso em maior atividade interna de P\&D e treinamento de pessoal.

Metodologicamente, essa alteração de formulação de hipóteses levou à utilização de metodologias econométricas que buscassem controlar para autosseleção, ou por meio da estimação de modelos de equações simultâneas na forma proposta por Clerides, Lach e Tybout (1998), ou por utilização de técnicas de matching. Os respectivos objetivos dessas metodologias são o de assegurar que seja considerada a simultaneidade entre a decisão de exportar e a performance produtiva da firma, ou então que sejam promovidas comparações de desempenho produtivo entre firmas que possuam em um instante inicial a mesma chance de entrar no mercado internacional. Wagner (2007) ainda relata o emprego de testes de dominância estocástica da distribuição de produtividade dos exportadores sobre a distribuição de produtividade para os não exportadores.

Com relação ao caso brasileiro, Markwald e Puga (2002), ao discutirem sobre a aplicabilidade de políticas de promoção de exportações, argumentam a favor de políticas horizontais para redução dos custos de entrada na exportação e no fortalecimento do desempenho da base exportadora existente. Seus argumentos centram-se na hipótese de autosseleção e na maior eficácia que as políticas de promoção podem ter sobre a base exportadora existente em razão dos diferenciais de produtividade já alcançados pelas empresas exportadoras. Baseados em dados sobre a performance exportadora das empresas iniciantes no mercado externo, apontam para diversos fatos estilizados que contribuem para a aceitação da hipótese de autosseleção. Entre esses fatos, alguns são interessantes destacar, como a baixa contribuição relativa das empresas iniciantes no total exportado, o elevado índice de desistência das empresas exportadoras e a evolução diferenciada das empresas exportadoras que permanecem continuamente no mercado externo. Esses fatos sugerem, então, que existem empresas que estariam prontas para exportar e que, portanto, políticas de promoção de exportação do tipo "pick up the (potential) exporters" seriam dispensáveis.

Muendler (2004) apresenta resultados para a indústria brasileira que vão de encontro à hipótese de autosseleção, demonstrando que uma maior produtividade aumenta a chance de não exportadores tornarem-se exportadores, reduzindo, por outro lado, a chance de que exportadores desistam dessa atividade. Kannebley e Valeri (2006) investigam em que medida as condições iniciais das empresas estreantes, e em especial a realização de atividades inovativas, são importantes para determinar a maior permanência das empresas no mercado internacional. Nesse sentido, foram 
conduzidos testes empíricos para empresas estreantes nos anos 1998-2001, constituindo um conjunto de 1009 empresas estreantes, com resultados que confirmaram a hipótese de autosseleção, à medida que foi observado que empresas que apresentavam melhores condições produtivas iniciais, em termos de maior produtividade do trabalho, maior escala e menores custos e margem de lucro, também apresentaram maior probabilidade de permanecer, ou continuamente ou por mais tempo, na base exportadora. Adicionalmente, considerando apenas as empresas estreantes em 2001, também foi evidenciada uma relação diferenciada entre o padrão, ou o tempo de permanência, das empresas inovadoras e não inovadoras e as condições iniciais de entrada no mercado externo. Para as empresas não inovadoras, as condições iniciais mostraram-se mais relevantes para explicar sua permanência no mercado externo, ao contrário das empresas inovadoras, sugerindo que a realização de inovação tecnológica poderia incrementar a competitividade das empresas inovadoras, mesmo após sua entrada no mercado internacional, o que condiz com a hipótese de aprendizado pela exportação.

Especificamente sobre a hipótese de aprendizado pelas exportações para as firmas industriais brasileiras, Arbache (2005) procura investigar a relação de causalidade entre tecnologia, exportação e desempenho das firmas. Utilizando uma tipologia de empresas que distingue as firmas segundo sua capacidade de inovar e diferenciar produtos, empresas especializadas em produtos padronizados e empresas que não diferenciam produtos e tem menor produtividade, suas investigações centram-se sobre o impacto da inovação tecnológica e das exportações sobre definições alternativas de variáveis representativas da produtividade do trabalho e tamanho das firmas. Utilizando informações para o período 1997-2001, conduz uma análise contrafactual para diferentes combinações de tratamento baseados na realização de inovação e exportação. Considerando a restrição amostral desse trabalho, seus resultados sugerem que tanto inovação tecnológica quanto exportação implicaram um aumento de tamanho e melhoria de produtividade das firmas industriais relativamente às firmas não inovadoras/não exportadoras, levando-o à conclusão de que a competitividade das firmas brasileiras é sensível a incrementos em tecnologia e ao contato com os mercados internacionais. Araújo (2006) também evidencia a existência de ganhos de produtividade, emprego e renda do trabalho, posteriores à estréia no mercado internacional, para as firmas brasileiras. A partir de uma amostra de 7.666 firmas nacionais, entre 1997-2002, combinando o uso da técnica propensity score matching com modelos de diferenças em diferenças, conclui que a estréia no mercado internacional afeta positivamente a produtividade, com estimativas que variam de $1,1 \%$ a $23,7 \%$ de acordo com a medida de produtividade. Entretanto, são observados ganhos de produtividade consistentes somente para as firmas que estréiam e permanecem no mer- 
cado. Kannebley et al. (2009) calcularam, de modo similar à Bernard e Jensen (1999), o prêmio de produtividade para as empresas industriais estreantes entre 2000 e 2001 para o período 1999-2003. Utilizando uma distinção entre as firmas que entraram e permaneceram continuamente no mercado, as que exportaram ocasionalmente e aquelas que abandonaram o mercado após sua estréia, os autores observaram que o prêmio médio de produtividade ex-ante para as empresas estreantes em 2000 foi de $30 \%$, chegando em média a $43 \%$ em 2003 , enquanto que para as empresas estreantes em 2001 o prêmio ex-ante foi de 25\%, chegando em 2003 a 37\%. Entretanto, esses autores demonstram que esse resultado de ganhos ex-posts deveu-se, primordialmente, aos ganhos proporcionados pelas empresas que exportaram continuamente no período, atingindo prêmios de produtividade da ordem de $55 \%$ e $46 \%$, respectivamente, para as firmas estreantes em 2000 e 2001.

\section{CONSIDERAÇÕES FINAIS}

Essa resenha se propôs a promover a integração de diversos resultados da literatura empírica internacional e nacional sobre o tema geral da relação entre exportações e produtividade. Mais especificamente, sobre o papel dos custos de entrada, autosseleção, aprendizado e liberalização comercial sobre a evolução da produtividade das firmas e, em particular, das firmas exportadoras.

Em termos gerais, o que é possível observar é a existência de uma convergência de resultados no que diz respeito aos temas de histerese e autosseleção nas exportações das firmas industriais. Essas evidências são reforçadas pela aceitação da hipótese de existência de custos de entrada ou de saída da atividade exportadora e consequente presença de histerese nas exportações de produtos manufaturados brasileiros, em concordância com as evidências internacionais.

Já para o tema do aprendizado, as evidências produzidas para o caso brasileiro indicam, em concordância para os casos de países em desenvolvimento, a possibilidade de ganhos ex-post de produtividade. No estágio atual da literatura, ainda não existem evidências conclusivas sobre a origem desses ganhos ex-post. Isto é, se seriam provenientes de um contato com um mais amplo conjunto de informações externas, e/ou reflexo de um esforço tecnológico mais intenso posteriormente à estréia no mercado internacional.

Contudo, foi observado conjuntamente que os processos de autosseleção e aprendizado tendem a ser conduzidos por um mesmo subconjunto de empresas, ou seja, aquelas que estréiam com maior valor exportado e permanecem continuamente na base exportadora. Essas são as empresas que também obtêm a maior parcela de ganhos ex-post de produtividade. Definitivamente, essas questões merecem um maior desenvolvimento para sua compreensão, além de também merecerem atenção 
explicações para a desistência na atividade exportadora, o que seria do ponto de vista de efetividade de políticas de comércio exterior de extremo interesse.

Em relação aos resultados para os impactos de processos de liberalização comercial sobre a produtividade da indústria, enquanto a literatura comercial apresenta evidências favoráveis à expansão da atividade exportadores nos países e conseqüentes efeitos de realocação sobre a variação da produtividade, o mesmo aparentemente não é verificado no caso brasileiro. Ainda que não tenha sido produzido nenhum estudo sobre o impacto da realocação de mercado sobre a produtividade, a combinação de indicações sugeridas por Castro (2001) a respeito do foco de resposta para o mercado interno, somada aos resultados de indicadores de orientação externa para o agregado dos setores industriais e das firmas industriais, sugere que muito dificilmente o aumento de produtividade verificado nos anos de 1990 tenha qualquer relação com algum efeito de realocação. Os resultados produzidos a partir de informações de firmas industriais indicam que os ganhos de produtividade foram induzidos pelo aumento da pressão competitiva das importações sobre os mercados de bens e pela crescente adoção de insumos e equipamentos importados. Nesse tópico, a literatura para o caso brasileiro tem um caminho a percorrer, já aberto pela literatura internacional, no que concerne à decomposição dos ganhos de produtividade, à influência das importações e a diversificação da produção.

\section{REFERÊNCIAS}

ALVAREZ, R.; LÓPEZ, R. “Exporting and Performance: Evidence from Chilean Plants”. The Canadian Journal of Economics,v. 38, n. 4, p. 1.384-1.400, 2005.

ARAÚJO, B. C. P. O. Análise Empírica dos Efeitos ex-post das Exportações sobre a Produtividade, o Emprego e a Renda das Empresas Brasileiras. In: XXXIV Encontro Nacional de Economia - Salvador: ANPEC, 2006.

ARBACHE, J. S. “Inovações Tecnológicas e Exportações Afetam o Tamanho e a Produtividade das Firmas Manufatureiras? Evidências para o Brasil” In: Inovações, Padrões Tecnológicos e Desempenho das Firmas Industriais Brasileiras, Brasília: Ipea, 2005.

AW, B. Y.; ROBERTS, M. J. ; WINSTON, T. "Export Market Participation, Investments in R\&D and Worker Training, and the Evolution of Firm Productivity". The World Economy, p. 83-104, 2007.

BALDWIN, J. R.; GU, W. “Trade Liberalization: Export-Market Participation, Productivity Growth, and Innovation". Oxford Review of Economic Policy, v. 20, n. 3, p. 372-391, 2004.

BALDWIN, R. "Hysteresis in Trade", MIT mimeo prepared for 1986 NBER Summer Institute, April 1986.

BALDWIN, R. "Hysteresis in Import Prices: the beachhead effect". American Economic Review, v. 78 , n. 4 , p. $773-785,1988$. 
BALDWIN, R.; KRUGMAN, P. R. “The Persistence of the U.S. Trade Deficit”. Brooking Papers on Economic Activity, v. 1, p. 1-55, 1987.

BERNARD A. B.; EATON, J. ; JENSEN, J. B.;KORTUN, S. "Plants and Productivity in International Trade”. The American Economic Review, v. 93, n. 4, p. 1.268-1290, 2003.

BERNARD A. B.; JENSEN, B. “Exceptional Exporter Performance: Cause, Effect or Both?”. Journal of International Economics, v. 47, p. 1-25, 1999

"Why Some Firms Export". The Review of Economics and Statistics, May, 2004, v. 86, n. 2, p. 342-57, 2004.

"Exporting and Productivity in the USA". Oxford Review of Economic Policy, v. 20, n. 3, p. 372-391, 2004.BLALOCK, G.; GERTLER, P. J. "Learning from Exporting Revisited in a Less Developed Setting” Journal of Development Economics, v. 75, p. 346-416, 2004.

CASTRO, A. B. "A Reestruturação Industrial Brasileira nos Anos 90. Uma Interpretação". Revista de Economia Política, v. 21, n. 3, 2001.

CLERIDES, S. K.; LACH, S.; TYBOUT, J. R. "Is Learning by Exporting Important? MicroDynamic Evidence from Colombia, Mexico, and Morroco". Quarterly Journal of Economics, v. 113 , n. 3 p. $903-948,1998$.

DAVIS, D. R.; WEINSTEN, D. E. What Role for Empirics in International Trade. NBER Working Paper 8453, 2001.

DIXIT, A. K. Hysteresis, Import Penetration, and Exchange Rate Pass-Through. Quarterly Journal of Economics, v. 104, n. 2, p. 205-228, 1989.

DIXIT, A. K.; STIGLITZ, J. Monopolistic Competition and Optimum Product Diversity. American Economic Review, v. 67, n. 3, p. 297-308, 1977.

FEENSTRA, R. C. "New Evidence on the Gains from International Trade" Review of World Economics, v. 142, n. 4, p. 617-641, 2006.

FERREIRA, P. C.; ROSSI, J. L. "New Evidence from Brazil on Trade Liberalization and Productivity Growth" International Economic Review, v. 44, n. 4, p. 1.383-1.405, 2003.

FONSECA, R.; CARVALHO, M. C. JR; POURCHET, H. "A Orientação Externa da Indústria de Transformação Brasileira após a Liberalização Comercial” et al. Revista de Economia Política, v. 20, n. 3, 2000.

GÖCKE, M. "Various Concepts of Hysteresis Applied in Economics". Journal of Economic Surveys, v. 16, n. 2, p. 167-88, 2002.

GREENWAY, D.; KNELLER, R. "Firm Heterogeneity, Exporting, and Foreign Direct Investiment”. The Economic Journal, v. 117, p. 134-161, 2007.

GROSSMAN, G. M.; HELPMAN, E. "Quality Ladders and Product Cycles" The Quaterly Journal of Economics, v. 106, n. 2, p. 557-586, 1991a.

"Endogenous Product Cycles" The Economic Journal, v. 101, n. 408, p. 1.214$1.229,1991 b$. 
HELPMAN, E. "International Trade in the Presence of Product Differentiation, Economies of Scale, and Imperfect Competition: A Chamberlin- Heckscher-Ohlin Approach" Journal of International Economics, v. 11, p. 305-340, 1981.

"The Structure of Foreign Trade". The Journal of Economic Perspectives, v. 13, n. 2, p. 121-144, 1999.

KANNEBLEY, S. JR; VALERI, J. O. "Persistência e Permanência Na Atividade Exportadora: Uma Análise Empírica Para As Empresas Industriais Brasileiras” in Empresas Brasileiras no Comércio Internacional, Brasília: IPEA, 2006

KANNEBLEY, S. JR; ESTEVES, L. A.; SILVA, A. M.; ARAÚJO, B. C. P. "Autosseleção e aprendizado no comércio exterior das firmas industriais brasileiras" ECONOMIA REVISTA DA ANPEC, v. 10, n. 4, Selecta 2009, p. 715-740.

KRUGMAN, P. R. "Increasing Returns, Monopolistic Competition, and International Trade" Journal of International Economics, v. 9, n. 4, p. 469-79, 1979.

"Scale Economies, Product Differentiation, and the Pattern of Trade". American Economic Review, v. 70, p. 950-959, 1980.

Exchange-Rate Instability, Massachussetts: Cambridge MIT Press, 1989.

LISBOA, M. B.; MENEZES FILHO, N. A.; SCHOR, A. The Effects of Trade Liberalization on Productivity Growth in Brazil: Competition or Technology? Revista Brasileira de Economia, v. 64, n. 3, p. 277-289.

LEAMER, E. E.; LEVINSHON, J. "International Trade Theory: The Evidence”. NBER Working Paper n. 4.940, 1994.

MARKWALD , R. "O Impacto da Abertura Comercial sobre a Indústria Brasileira: O Balanço de uma Década” Revista Brasileira de Comércio Exterior, v. 68, p. 4-25, 2001.

MARKWALD, R.; PUGA, F. P. Focando a Política de Promoção às Exportações; In: O Desafio das Exportações, Rio de Janeiro: BNDES, dez., 2002.

MOTTA VEIGA, P.; MARKWALD, R. A Micro, Pequenas e Médias Empresas na Exportação: desempenho no Brasil e lições da experiência internacional. Texto para Discussão FUNCEX, n. 136, 1998.

MAYERGOYZ, I. D. "Mathematical Models of Hysteresis" Physica Review Letters, v. 15, p. 1.518-1.521, 1986.

MELITZ, M. "The Impact of Trade on Intra-Industry Reallocations and Aggregate Productivity". Econometrica, v. 71, n. 6, p. 1.695-1.725, 2003.

MUENDLER, M.A. “Trade, Technology, and Productivity: A Study of Brazilian Manufactures: 1986-1998” CESifo Working Paper. 148, March, 2004.

PARSLEY, D. C.; WEI, S-J. Insignificant and Inconsequential Hysteresis: the case of U.S. bilateral trade The Review of Economic Statistics, v. 75, n. 4, p. 606-13, November, 1993.

PISCITELLI, L.; CROSS, R.; GRINFELD, M.; LAMBA, H. "A Test for Strong Hysteresis". Computational Economics v. 15, p. 59-78, 2000. 
ROBERTS, M. J.; TYBOUT, J. R. “The Decision to Export in Colombia: an empirical model to entry with sunk costs”. American Economic Review, v. 87, n. 4, p. 545-564, 1997.

SCHOR, A. "Heterogeneous Productivity Response to Tariff Reduction. Evidence from Brazilian Manufacturing Firms" Journal of Development Economics, v. 75, p. 373-396, 2004.

VAN BIESEBROECK, J. "Exporting Raises Productivity un Sub-Saharan African Manufacturing Firms". Journal of International Economics, v. 67, p. 373-391, 2005.

WAGNER, J. "Exports and Productivity: A Survey of the Evidence from Firm-Level Data". The World Economy, p. 60-82, 2007. 